$\xi$

\title{
Activated Carbon Production from Waste Biomass
}

\author{
${ }^{*}$ Rajamani. $\mathbf{R}^{1}$, Vinoth kumar. ${ }^{2}$, Sujith. $\mathrm{A}^{3}$ and Karthick. $\mathrm{E}^{4}$ \\ ${ }^{1,2,3,4}$ Department of Chemical Engineering \\ ${ }^{1}$ Department of Chemical Engineering, Vel Tech High Tech Dr.Rangarajan Dr.Sakunthala Engineering College, Avadi, Chennai-62, India. \\ *Corresponding author E-mail: kingcash2010@gmail.com, vinothkumarpetro@gmail.com
}

\begin{abstract}
:
Activated carbon is used as filter medium for the removal of hazardous particles in exhaust gases, in the purification of water and also in waste water treatment. Activated carbon is used in gas purification, water purification, sewage treatment and many other applications. This concept is used to satisfy the continuously increasing demand of activated carbon at low cost.The textile industry is one of the largest producers of dye effluent. Treatment of these effluents has to be cost effective hence a number of precursors have been studied as a viable alternative adsorbent. The present work relates to efforts made towards developing a high surface area activated carbon produced from the fruit shells of sterculia foetida by chemical activation process with phosphoric acid as the activating agent the fruit shell of sterculia foetida constitute a novel precursor for the preparation of activated carbon which has not yet been identified as a source for carbon material. Experiments were conducted in lab scale using muffle furnaces under static conditions in a self-generated atmosphere covering process parameters such as Impregnation Ratio (IR), Carbonization time and Temperature. The process parameters are characterized and optimized based on the Methylene Blue number, Methyl Violet Number and the Iodine number.

The adsorption of reactive orange dye onto fruit shell of sterculia foetida activated carbon from aqueous solution was investigated. The process is carried out varying the process parameters as Impregnation Ratio (1:1 to 1:6), Activation Temperature (300 to $\left.800{ }^{\circ} \mathrm{C}\right)$ and Activation Time (60 to $210 \mathrm{~min}$ ).
\end{abstract}

Keywords: Activated carbon, sterculia foetida, phosphoric acid, reactive orange dye, Impregnation Ratio, Activation Temperature, Activation Time, Methylene Blue Number, Methyl Violet Number and Iodine Number.

\section{Introduction}

Water pollution is becoming an increasingly serious problem, especially in developing countries, due to the lack of funds available for investment in waste water treatment. At present, organic pollution is more serious than inorganic pollution. The micro pollutants generally enter surface water through discharges and effluents from various industrial processes. These include the petrochemical industry, food stuff, dyestuff and chemical industries such as paper, fertilizer, plastic and metal finishing etc..,. The presence of organic pollutants in water has aroused much attention in recent decades because of their potential mutagenicity, carcinogenicity and toxicity. Moreover, they lead to undesirable effects in the color, odour and taste of drinking water. It has been demonstrated that convectional treatment processes like membrane filtration, sedimentation, flocculation, ion exchange and coprecipitation/adsorption [1]. The shortcomings of most of these methods are high operational and maintenance costs, high energy consumption and complicated procedure involved in this process. Further generation of toxic sludge is another serious problem, the disposal of which addsfurther burden on the techno-economic feasibility of this treatment process. Comparatively, adsorption seems to be a more attractive method in water pollution control in terms of cost, simplicity of design and operation [2].

By using waste biomass which has no other end use the cost of activated carbon can be reduced and it also a way of efficient usage of the waste biomass. Many researchers have been carried out on study of activated carbon produced from various biomasses such as coconut shells, walnut shells, sunflower shells, coffee waste, olive stones, wheat straw, rice straw, Sugar cane bagasse, Pomegranate peel, Mahogany sawdust, cassava peel, date pit, fruit stones and nutshell jute fiber etc. In this work, the selected biomass is the shells of sterculia foetida.

In this study, the activated carbon production involves impregnation of the biomass with phosphoric acid and later carbonised in muffle furnace. The objective of this work is to optimize the process parameters in the production of activated carbon from sterculia foetida. The process parameters to be optimizes are impregnation ratio, activation time activation temperature. The procedure is repeated by varying process parameters that is impregnation ratio, activation time activation temperature. Thus produced activated carbon's characteristics are studied by Methylene blue, methyl violet analysis and iodine number test.

\section{Experimental}

\subsection{Materials Used To Prepare Activated Carbon}

\subsubsection{Collected biomass}

The collected biomass was rich in cellulosic content and it was best suited to prepare the activated carbon. 


\subsubsection{Activating Agent and Chemicals}

It was found from the literature that the best activating agent for cellulosic material was Phosphoric acid $\left(\mathrm{H}_{3} \mathrm{PO}_{4}\right)$. Hence for the selected biomass Phosphoric acid supplied by Central Drug House (P) Ltd., India was used as activating agent for the preparation of activated carbon. All the reagents used were of analytical grade and distilled water was used in sample preparation. Sodium carbonate, sodium hydroxide and potassium iodide were obtained from Sisco research laboratories pvt, Ltd., Methylene blue from Ranbaxy laboratories Ltd., potassium iodate from Qualigens fine chemicalsBombay. $\mathrm{HCl}$ from Marck Specifications Pvt, Ltd., Iodine from RFCL limited -New Delhi. $\mathrm{H}_{3} \mathrm{PO}_{4}$ from Central Drugs House Pvt, Ltd., Sodium Thiosulphate from SD fine- chem. Limited.

\subsubsection{Chemical Activation Using $\mathrm{H}_{3} \mathrm{PO}_{4}$ as an Activating Agent}

The process of activation carried out in presence of activating agents either in the form of solid state (or) liquid state is called as chemical activation. In general, as corrosive chemicals like $\mathrm{NaOH}$ and $\mathrm{H}_{2} \mathrm{SO}_{4}$ are involved in this process, chemical activation is regarded as environmentally unfriendly. But the carbon yields will be higher and also lower temperature of activation is sufficient in the case of chemical activation relative to physical activation. Several dehydrating agents like $\mathrm{KOH}, \mathrm{NaOH}, \mathrm{H}_{3} \mathrm{PO}_{4}, \mathrm{ZnCl}_{2}, \mathrm{Na}_{3} \mathrm{PO}_{4}, \mathrm{NaCl}$, $\mathrm{KMnO}_{4}$, were used on various raw materials to yield appreciable quality of activated carbon. Among the several dehydrating agents, Zinc chloride and phosphoric acid are widely employed for commercial manufacture due to its excellent dehydration characteristics. In the current study, $\mathrm{H}_{3} \mathrm{PO}_{4}$ is used as an activating agent.

\subsubsection{Carbonization of the Biomass}

In the chemical method, the starting biomass material (shells of Sterculia foetida) obtained was cut into the approximately uniform pieces, dried in the hot air oven and impregnated with varying impregnation ratio of phosphoric acid for a period of $24 \mathrm{hr}$, the acid was decanted and the biomass were carbonized in the muffle furnace in the absence of air at varying activation temperature and activation time.

The activated carbon thus obtained was washed with distilled water to remove residual acids present in it and the then dried in a hot air oven at $110^{\circ} \mathrm{C}$. The drying was continued until a constant weight of activated carbon was reached. That Sterculia foetida activated carbon was crushed and sieved using 170 meshes (BSS) screen to obtained uniform particle size of adsorbents.

The taken biomass is the new source, so to find out the exact operating parameters such as the time and temperature of activation and impregnation ratio on the product quality. The product quality is characterized based on the Methylene blue number and the Iodine number.

\subsubsection{Estimation of Methylene Blue, Methyl Violet and Iodine Number}

The end product is characterized by Methylene blue, Methyl Violet and Iodine number.

\subsubsection{Methylene Blue Number}

It indicates the measure of mesopore of the activated carbon and it is defined as the milligrams of Methylene blue adsorbed per gram of carbon. Methylene blue represents the surface area contributed by the pores of $(0-500 \AA)$. Methylene blue was chosen in this study because of its known strong adsorption onto solids and its

recognized usefulness in characterizing adsorptive material. Methylene blue has a molecular weight of $373.9 \times 10-3 \mathrm{~kg} \mathrm{~mol}^{-1}$.

\subsubsection{Methyl Violet Number}

Methyl violet test is similar to the Methylene blue test; it gives the indication of the surface area available, which is the adsorption capacity of the activated carbon.

\subsubsection{Iodine Number}

The Iodine test is a test method that covers the determination of the relative activation level of activated carbons by the adsorption of iodine from aqueous solution. The amount of iodine adsorbed (in milligrams) by $1 \mathrm{~g}$ of carbon using test conditions is called the iodine number. The iodine number is a relative indicator of porosity in an activated carbon. Iodine number is a rough measure of capacity of small molecules and correlates with surface area (Keller et al., 1987) and may be used as an approximation of surface area for activated carbons. This test method for specific surface area of carbon of ASTM standard (C819).

\section{Results and Discussion}

\subsection{Optimization of Carbon Preparation Parameter}

The source (Sterculia foetida) obtained was cut into small pieces, dried and impregnated with varying impregnation ratio $(1: 1$ to $1: 6)$ of phosphoric acid for a period of $24 \mathrm{hrs}$, then the acid was filtered and biomass were carbonized in muffle furnace in the absence of air at varying activation temperatures (300 to $800^{\circ} \mathrm{C}$ ) and varying activation time (60 to 210 mins). The activated carbon was washed using distilled water to remove the acid. It was then dried till a constant weight was achieved. The activated carbon crushed and sieved in 170 mesh standard sieve. The activated carbon was then stored in an airtight container.

\subsection{Effect of Impregnation Ratio}

The impregnation ratio is given by, Impregnation ratio $=($ weight of acid): (weight of biomass).

The various impregnation ratios of (1:1 to $1: 6)$ Methylene blue, Methyl Violet and Iodine number were determined. It has been tabulated in the table: 1 for an impregnation range of 1:5 gives the maximum value of Methylene blue (57), Methyl Violet (71.25) and Iodine number (1103) was obtained.

The iodine number of $1103 \mathrm{mg} \mathrm{g}^{-1}$, which is much greater than Methylene blue number and methyl Violet number of 57 and 71.25 $\mathrm{mg} \mathrm{g}^{-1}$ indicates that the prepared activated carbon is more of micro pores and less in mesopore, When the impregnation ratio increases, the more swelling of the material and hence stronger release of volatiles leading to increased pores.

Table 1: Impregnation Ratio:

\begin{tabular}{|l|l|l|l|l|l|l|}
\hline $\begin{array}{l}\text { Impregnation } \\
\text { Ratio (IR) }\end{array}$ & $1: 1$ & $1: 2$ & $1: 3$ & $1: 4$ & $\mathbf{1 : 5}$ & $1: 6$ \\
\hline $\begin{array}{l}\text { Methylene Blue } \\
\text { Number } \\
\left(\mathbf{m g ~ g}^{-1}\right)\end{array}$ & 31.5 & 41.2 & 44.2 & 47.2 & $\mathbf{5 7}$ & 42 \\
\hline $\begin{array}{l}\text { Methyl Violet } \\
\text { Number } \\
\left(\mathbf{m g ~ g}^{-1}\right)\end{array}$ & 38.2 & 40.5 & 47.2 & 58.5 & $\mathbf{7 1 . 2}$ & 45.7 \\
\hline $\begin{array}{l}\text { Iodine Number } \\
\text { (mg g-1) }\end{array}$ & 701 & 765 & 791 & 941 & $\mathbf{1 1 0 3}$ & 859 \\
\hline
\end{tabular}


Based on the above values the graph was drawn between Methylene blue number Vs Impregnation Ratio, Methyl violet Vs Impregnation Ratio and Iodine number Vs Impregnation Ratio.

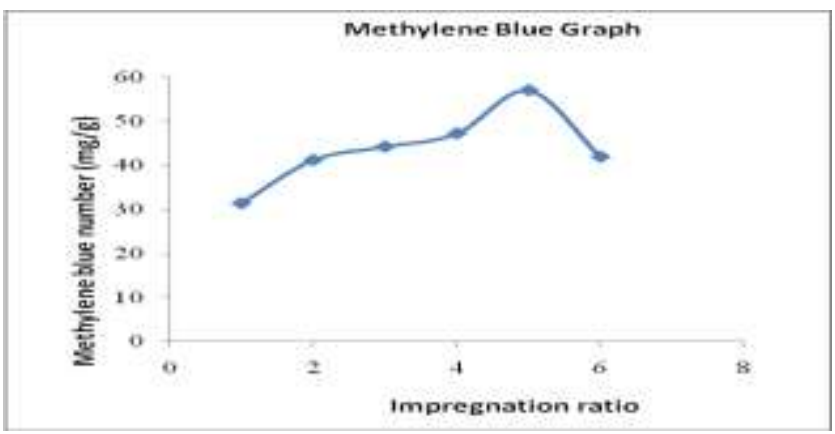

Fig 3.1: Effect of Impregnation ratio on Methylene Blue Number

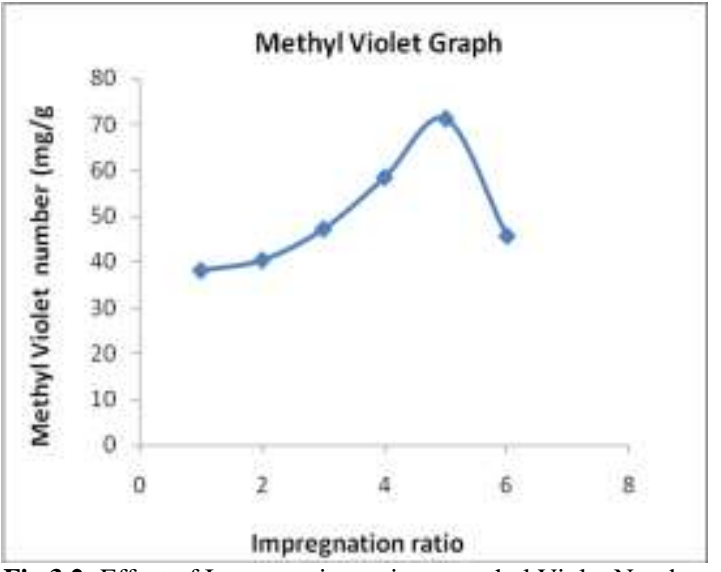

Fig 3.2: Effect of Impregnation ratio on methyl Violet Number

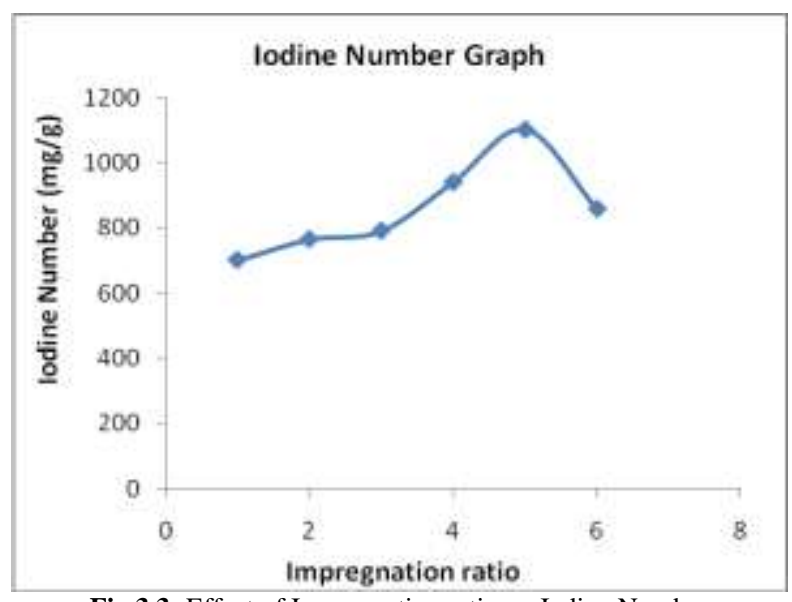

Fig 3.3: Effect of Impregnation ratio on Iodine Number

\subsection{Effect of Temperature}

The Impregnation ratio is fixed as (1:5) by varying the temperature as range of $\left(300\right.$ to $\left.800^{\circ} \mathrm{C}\right)$ for this range the Methylene blue ,Methyl Violet and the iodine number were determined. It has been tabulated in the table: 2 for the temperature range of $700^{\circ} \mathrm{C}$ gives the maximum value of Methylene blue (61.25), Methyl Violet (80.25) and Iodine (1778). The iodine value of $1778 \mathrm{mg} \mathrm{g}^{-1}$ which is much greater than Methylene blue number of $\mathrm{mg} \mathrm{g}^{-1}$ indicates that the prepared activated carbon is more of micro pores and less in mesopore. Higher temperature makes the substances which stay deeply in the particle have the chance to disintegrate and explode.
Table2: Activation temperatures

\begin{tabular}{|c|c|c|c|c|c|c|}
\hline Temperature $\left({ }^{\mathbf{0}} \mathbf{C}\right)$ & 300 & 400 & 500 & 600 & $\mathbf{7 0 0}$ & 800 \\
\hline $\begin{array}{c}\text { Methylene Blue } \\
\text { Number } \\
\left(\mathbf{m g ~ g}^{-1}\right)\end{array}$ & 42.7 & 49.5 & 54 & 56.25 & $\mathbf{6 1 . 5}$ & 53.25 \\
\hline $\begin{array}{c}\text { Methyl Violet } \\
\text { number } \\
\left(\mathbf{m g ~ g}^{-1}\right)\end{array}$ & 57 & 64.5 & 66.75 & 69 & $\mathbf{8 0 . 2}$ & 66 \\
\hline $\begin{array}{c}\text { Iodine Number } \\
\left(\mathbf{m g ~ g}^{-1}\right)\end{array}$ & 846 & 941 & 1116 & 1252 & $\mathbf{1 7 7 8}$ & 1549 \\
\hline
\end{tabular}

Based on the above values the graph was drawn between Methylene blue number Vs Temperature, Methyl Violet Vs Temperature and Iodine number Vs Temperature.

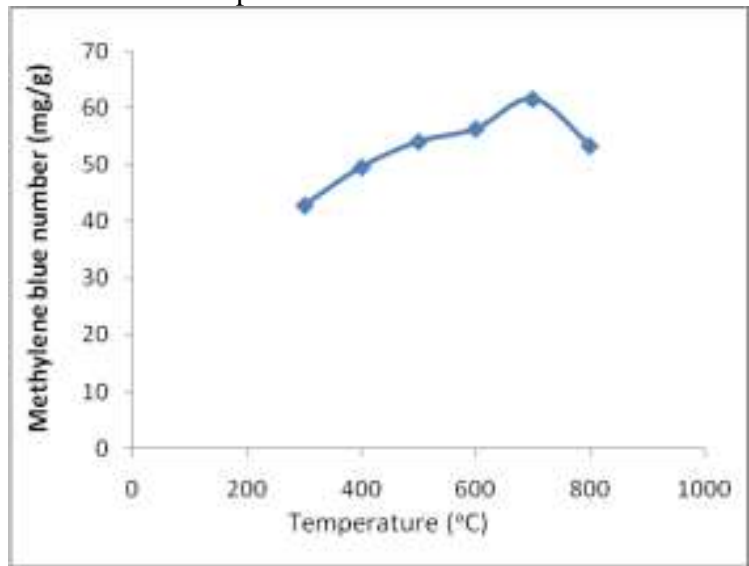

Fig 3.4: Effect of temperature on Methylene number

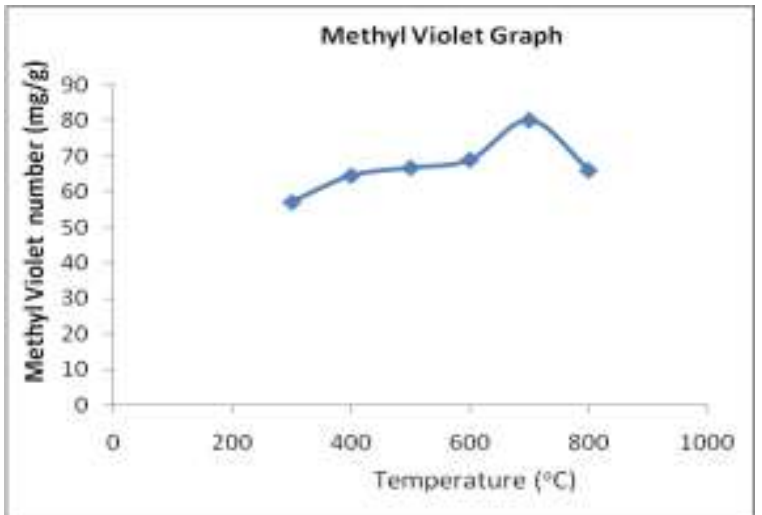

Fig 3.5: Effect of temperature on methyl violet number

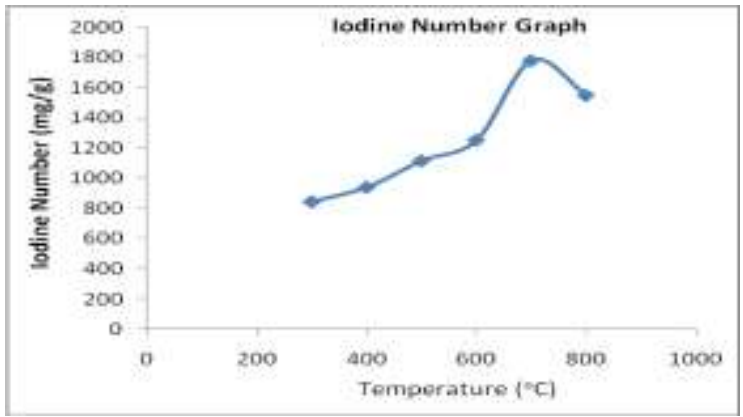

Fig 3.6: Effect of temperature on Iodine number

\subsection{Effect of Time}

The Impregnation Ratio (1:5) and Activation Temperature $\left(700^{\circ} \mathrm{C}\right)$ is fixed by varying the activation times as (60 to $180 \mathrm{mins}$ ) for this range the Methylene blue, Methyl violet and the Iodine number were 
determined. It is tabulated in the table 3 from these values at the time of (90 min) gives the maximum value of Methylene blue (63), Methyl Violet (81) and Iodine (1725).The obtained values will compare with the literature; it shows the Methylene blue value is in mesopore structure and the Iodine number value is in micro pore structure. This could be attributed to the fact that when increasing the time of carbonization, some volatile compounds which were in the inner part of particle could evaporate more with longer carbonization time.

Table 3: Activation time

\begin{tabular}{|l|l|l|l|l|l|l|}
\hline Time(min) & 60 & $\mathbf{9 0}$ & 120 & 150 & 180 & 210 \\
\hline $\begin{array}{l}\text { Methylene } \\
\text { Blue } \\
\text { Number(mg g- } \\
\mathbf{1})\end{array}$ & 57 & $\mathbf{6 3}$ & 54.75 & 51 & 44.25 & 40.5 \\
\hline $\begin{array}{l}\text { Methyl Violet } \\
\text { number (mg g- } \\
\mathbf{1})\end{array}$ & 77.25 & $\mathbf{8 1}$ & 73.5 & 68.25 & 61.5 & 57.75 \\
\hline $\begin{array}{l}\text { Iodine } \\
\text { Number(mg g- } \\
\mathbf{1})\end{array}$ & 1400 & $\mathbf{1 7 2 5}$ & 1292 & 1170 & 1076 & 981 \\
\hline
\end{tabular}

Based on the above values the graph was drawn between Methylene blue number Vs Time, Methyl Violet Vs Time and Iodine number Vs Time.

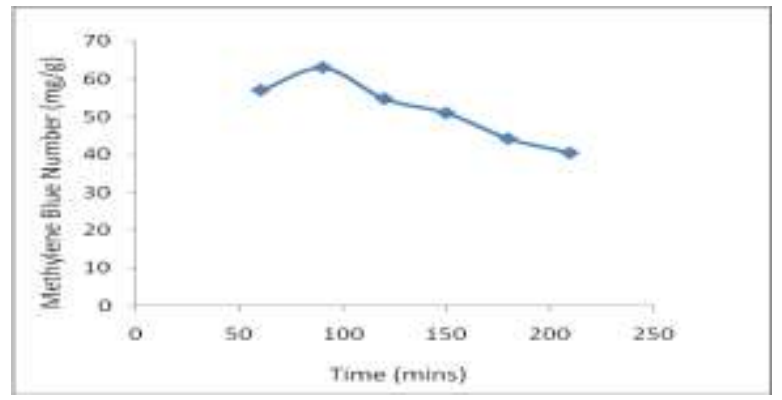

Fig 3.7: Effect of Time on Methylene number

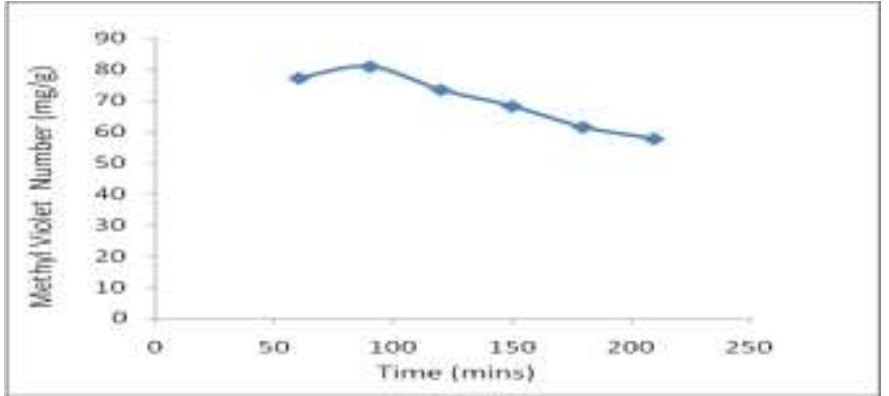

Fig 3.8: Effect of Time on methyl violet number

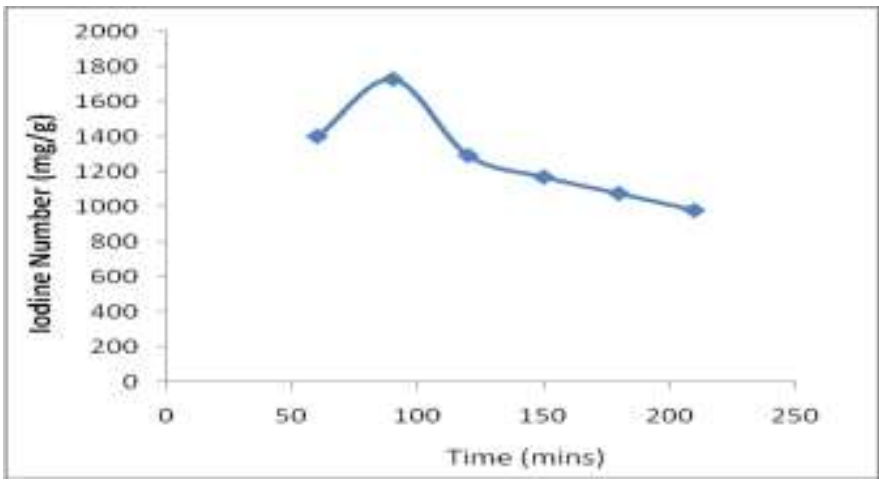

Fig 3.9: Effect of Time on Iodine number

\section{Conclusion}

The present investigation evaluates that the activated carbon made from sterculia foetida is used as an effective and economic adsorbent. The fruit shells of Sterculia foetida were found to be a promising precursor for the production of activated carbon materials. The detailed study on the process for activated carbon from Sterculia foetida using phosphoric acid as activating agent has been carried out. The optimum condition for activation is found to be the impregnation ratio of $\mathbf{1 : 5}$, Activation Temperature is $\mathbf{7 0 0}^{\circ} \mathbf{C}$ and Activation Time is 90 min.

Further studies required to predict better adsorption capacity. That is various experimental parameters such as effect of contact time, initial concentration of dye, adsorbent dosage, $\mathrm{pH}$ and temperature. The theories of Freundlich and Langmuir adsorption isotherm were used to describe the adsorption process of dye.

\section{References}

[1] S.E. Bailey, T.J.Olin, R.M.Bricka, D.D.Adrian, Effect of Preparation conditions of activated carbon from bamboo waste for real waste water. Journal of Hazardous Materials, Vol.173, pp1-3, (1999) 2469.

[2] S.D.Faust, O.M.Aly, Characterization of mango pit as a raw material in the preparation of activated carbon for waste water treatment, Biochemical engineering Journal,vol.36,No.3, (2007), PP.(230238),ISSN 1369-703x.

[3] R.C.Bansal, M.Goyal, the production of chemically Activated carbon. Carbon, Vol.37 NO.2. (1999), pp. (269-274), ISSN0008-6223.

[4] Savova D, Apak E, Ekinci E, Yardim F, Petrova N, Budinova T, Biomass conversion to Carbon Adsorbents and gas. Biomass Bio energy (2001) pp 21:133-42.

[5] Allen,S.J., L. Whitten and G.McKay,(1998), The production and characterization of activated carbons: A Review, Dev.Chem.Eng.Mineral process, (2002) pp 6(5),231-261.

[6] Putun AE, Ozbay N, Onal EP, Putun E. Fixed-bed Pyrolysis of cotton stalk for Liquid and solid products. Fuel Process Techno (2005) pp $86 ; 1207-19$.

[7] Tasi W T, Chang C Y, Lee SL. Preparation and Characterization of activated carbon from corn cob. Carbon (1997) pp 35:1198-200.

[8] Zhang T, Walaender WP, Fan LT, Fan M, Daugaard D, Brown RC. Preparation of Activated Carbon from Forest and Agricultural residues. Chem Eng J (2004) pp 105:53-9.

[9] O. Ioannidou, A. Zabaniotou Agricultural Residues as Precursors for activated carbon production- A Review of Renewable and Sustainable Energy Reviews.11 (2007) pp 1966-2005.

[10] Haykiri-acma H, Yaman S, Kucukbayrak S. Gasification of Biomass Chars in Steam- nitrogen mixture. Energy Conservation Management, (2005).pp 125 - 129.

[11] Aygun A, Yenisoy-Karakas S, Duman I. Production of granular activated carbon from fruit stones and nutshells and evaluations of their physical, Chemical and Adsorption Properties. Micro pore Mesopore Matter (2003) pp 66:189-95.

[12] Oh GH, Park CR. Preparation and characteristics of rice-straw-based porous carbons with high adsorption capacity. Fuel (2002) pp 81:32736.

[13] Savova D, Apak E,Ekinci E, Yardim F, Petrova N, Budinova T, Biomass Conversion to Carbon Adsorbents and gas. Biomass Bio energy (2001) pp 93:103-7.

[14] Amit Bhatnagar, A.K.Minocha Biosorption optimization of nickel removal from water using punica granatum peel waste. Colloids and surfaces B: Bio interfaces (2010) pp 544-548. 